\title{
Role of the ionic environment in enhancing the activity of reacting molecules in zeolite pores
}

\author{
Niklas Pfriem', Peter H. Hintermeier', , Sebastian Eckstein', Sungmin Kim², Qiang Liu ${ }^{1,3}$, Hui Shii, \\ Lara Milakovic', Yuanshuai Liu ${ }^{1,5}$, Gary L. Haller', Eszter Baráth', Yue Liu' ${ }^{1 *}$, Johannes A. Lercher,2* \\ ${ }^{1}$ Department of Chemistry and Catalysis Research Center, Technical University of Munich, Lichtenbergstrasse 4, 85747 Garching, Germany. ${ }^{2}$ Institute for Integrated

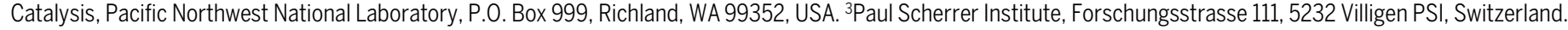 \\ ${ }^{4}$ School of Chemistry and Chemical Engineering, Yangzhou University, Siwangting Road 180, 225009 Yangzhou, Jiangsu, China. ${ }^{5}$ Qingdao Institute of Bioenergy and \\ Bioprocess Technology, Chinese Academy of Sciences, Songling Road 189, Laoshan District, Qingdao, China. \\ *Corresponding author. Email: yue.liu@tum.de (Y.L.); johannes.lercher@tum.de (J.A.L.)
}

Tailoring the molecular environment around catalytically active site allows to enhance catalytic reactivity via a hitherto unexplored pathway. In zeolites, the presence of water creates an ionic environment via formation of hydrated hydronium ions and the negatively charged framework Al tetrahedra. The high density of cation-anion pairs determined by the aluminum concentration of a zeolite induces a high local ionic strength that increases the excess chemical potential of sorbed and uncharged organic reactants. Charged transition states (carbocations for example) are stabilized, reducing the energy barrier and leading to higher reaction rates. Using the intramolecular dehydration of cyclohexanol on $\mathrm{H}-\mathrm{MFI}$ in water, we show quantitatively the enhancement of the reaction rate by the presence of high ionic strength as well as potential limitations of this strategy.

Zeolites, Brønsted- or Lewis-acidic microporous tectosilicates, are widely applied in chemical industry for sorption, separation, and catalysis (1-4). In the most classic case, the acid character is introduced by substitution of metal cations with a $3+$ formal charge (5). It has been speculated that the proximity of charge and dipoles in zeolite pores should give rise to strong field-effects, but the effects were not systematically quantifiable $(6,7)$. A long series of investigations has shown that Brønsted acid sites (BAS) have constant acid strength for sorption and catalysis, as long as the concentrations of substituting tetrahedral atoms did not exceed a certain threshold $(8,9)$. The high intrinsic catalytic activity of zeolites has, therefore, been attributed to the remarkable stabilization of transition states in the constraints of pores (1014).

Recent experiments showed that this beneficial aspect of transition state stabilization also holds true, when the catalyzed reaction is performed in the presence of water, allowing for the generation of hydrated hydronium ions $\left[\mathrm{H}_{3} \mathrm{O}^{+}\right.$hydr. $]$. The catalytic activity of these hydronium ions is up to two orders of magnitude higher than the respective specific activity of hydrated hydronium ions in an aqueous acid solution as probed by alcohol dehydration $(10,11,15)$. In the environment of the zeolites, the hydrated hydronium ions occupy a well-defined location at aluminum tetrahedra (that causes the BAS in the solid), are located in much closer proximity in zeolite pores than in the liquid phase. This proximity has been shown to lead to an increase in the activity coefficient of organic molecules in the zeolite pores, resembling the situation in aqueous phase in the presence of high concentrations of cations and anions of dissolved acids, bases, and salts (15). The direct consequence of the higher activity coefficient is a decrease of the interaction strength of the sorbed organic molecules, much like the decreasing interaction with the solvent in an aqueous solution of increasing density of cation anion pairs. This allows to rigorously translate the physical chemistry of non-ideality in an aqueous phase into the constraints of nanopores.

The higher activity coefficient is caused by an increase in the excess chemical potential compared to an ideal environment, for example, of a zeolite having no BAS. Conceptually, the increase in the excess chemical potential of the reacting molecule decreases the energy difference to the transition state and, in consequence, should lead to a higher rate, even if the transition state is not stabilized. In addition to that, a polar transition state will be stabilized by the polar environment compared to the uncharged reactant. It should be noted in passing that the confinement and the well-defined close spacing of hydrated hydronium ions additionally stabilizes the transition state, acting positively to reduce the free energy barrier in the confines of zeolites $(10,11)$.

We show in this contribution that such a scenario can be realized and that the combination of the increase in the thermodynamic activity of reacting molecules and the steric constraints of the zeolite pores leads to strong deviations from the expected sympathetic variation of catalytic activities with active sites of constant acid-base properties. We use the dehydration of cyclohexanol on a series of H-MFI zeolites with 
a wide range of $\mathrm{BAS}\left[\mathrm{H}_{3} \mathrm{O}^{+}{ }_{\text {hydr. }}\right]\left(0.05-0.86 \mathrm{mmol} / \mathrm{g}_{\mathrm{MFI}}\right)$ to show that the positive effect of enhancing the excess chemical potential of reacting molecules leads to an optimum density of active sites.

Catalyzed by hydrated hydronium ions $\left(\mathrm{H}_{3} \mathrm{O}^{+}{ }_{\text {hydr. }}\right.$ ), cyclohexanol dehydrates to cyclohexene in the aqueous phase on zeolite H-MFI. The reaction rate is independent of the aqueous phase concentration of cyclohexanol above $0.1 \mathrm{~mol} / \mathrm{L}$ (zero order reaction region, fig. S1). The rate normalized to the concentration of BAS, the turnover frequency (TOF), increased 6-fold from BAS concentration of 0.054 to 0.36 $\mathrm{mmol} / \mathrm{g}_{\mathrm{MFI}}$ and then decreased by $60 \%$ to BAS concentration of $0.86 \mathrm{mmol} / \mathrm{g}_{\mathrm{MFI}}$ (Fig. 1A). Concurrently, the activation energy decreased from $161 \mathrm{~kJ} / \mathrm{mol}$ to $140 \mathrm{~kJ} / \mathrm{mol}$ and increased to $158 \mathrm{~kJ} / \mathrm{mol}$ afterwards (Fig. 1B). In contrast, for gas phase reactions such as $n$-pentane cracking and 1-propanol dehydration, the variation in BAS concentration did not change the TOF, i.e., the acid strength of the sites involved can be considered as being constant (Fig. 1C). The identical catalytic activity of BAS in such a series of zeolites has been shown before for cracking $(16,17)$. It should be noted in passing that also the characterization with a base molecule showed an identical strength of the BAS (18). Although it has been reported that different $\mathrm{Al}$ locations influence catalytic activity of zeolites $(19,20)$, the constant TOFs of $n$-pentane cracking and 1-propanol dehydration on all the tested H-MFIs allows to exclude the probability of selective Al locations on any specific $\mathrm{T}$ sites or in pairs impacting reactivity.

Then, the question arises as to why BAS exhibited significant differences in the presence of water. To address this question, we analyze the differences of BAS induced by their environments. In the gas phase, BAS are predominately covalent hydroxy groups, located on oxygen bridging between silicon-oxygen and aluminum-oxygen tetrahedra in the zeolite. The hydroxy groups are moderately polar and have negligible volume. In water the BAS are converted to hydrated hydronium ions $\left(\mathrm{H}_{3} \mathrm{O}^{+}{ }_{\text {hydr. }}\right)$ bonded ionically to the zeolite framework, with a positive charge and a specific volume.

In contrast to homogenous solution in which $\mathrm{H}_{3} \mathrm{O}^{+}$hydr. are highly dispersed throughout the liquid volume, the $\mathrm{H}_{3} \mathrm{O}^{+}$hydr. in H-MFI are confined in the limited space of zeolite pores. Consequently, this leads to a very high local concentration that cannot be changed by adding more water. Figure $2 \mathrm{~A}$ (black) shows the concentrations of $\mathrm{H}_{3} \mathrm{O}^{+}$hydr. per $\mathrm{H}-\mathrm{MFI}$ unit cell varying between 0.3 - 5 in the samples tested, corresponding to a local density of $0.1-1.6 \mathrm{~mol} / \mathrm{L}$, using the $\mathrm{H}$ MFI unit cell volume of approximately $5.2 \mathrm{~nm}^{3}$ (21). If we consider further that the micropore volume of H-MFI is only $1.3 \mathrm{~nm}^{3}$ per unit cell $\left(\sim 0.14 \mathrm{~cm}^{3} / \mathrm{g}_{\mathrm{MFI}}\right.$, table $\left.\mathrm{S} 1\right)$, the $\mathrm{H}_{3} \mathrm{O}^{+}$hydr. has a molarity in the range of $0.4-6.4 \mathrm{~mol} / \mathrm{L}$ in the $\mathrm{mi}$ cropore space. Such high local concentrations of $\mathrm{H}_{3} \mathrm{O}^{+}$hydr. have two consequences, i.e., a very high local ionic strength and a competition between the $\mathrm{H}_{3} \mathrm{O}^{+}$hydr. and the substrate for the micropore space.

As an ion pair, $\mathrm{H}_{3} \mathrm{O}^{+}$hydr. with the corresponding anions, induces an ionic environment. In an aqueous homogenous electrolyte solution, this leads to non-ideality by which the ions (including $\mathrm{H}_{3} \mathrm{O}^{+}{ }_{\text {hydr. }}$ ) have concentration-dependent activity coefficients $(\gamma)$. A solute is stabilized $(\gamma<1)$ or destabilized $(\gamma>1)$ by the presence of a specific concentration of cations and anions, reflecting an increased or decreased excess chemical potential of the solute. The ionic strength $(I)$, is the most critical variable determining the extent of deviation from an ideal solution. It is defined as the sum of all product charge $\left(z_{i}\right)$ square weighted concentration $\left(c_{i}\right)$ of all the ions (Eq. 1). Thus, $\gamma$ is expressed as a function of $I, \gamma(I)$ :

$$
I=\frac{1}{2} \cdot \sum c_{i} z_{i}^{2}(1)
$$

Although classical ionic strength is defined for homogeneous solution, we have shown previously that the concept of non-ideality and ionic strength is transferrable to zeolites in water and applicable to quantitatively explain adsorption properties (15). By considering the zeolite to be a "quasi solid electrolyte", its local ionic strength in a micropore is also defined by Eq. 1 , with $z_{\mathrm{i}}$ being 1 and $c_{\mathrm{i}}$ being volumetric densities of $\mathrm{H}_{3} \mathrm{O}^{+}$hydr. and negatively charged framework site $\left(\mathrm{Z}^{-}\right)$in the micropores, i.e., concentration normalized to micropore volume. Figure 2A (blue) shows the ionic strength of the investigated $\mathrm{H}-\mathrm{MFI}$. Their high local concentration of $\mathrm{H}_{3} \mathrm{O}^{+}{ }_{\text {hydr. in }}$ H-MFI micropores induces high local ionic strength. For example, $\mathrm{H}-\mathrm{MFI}$ ( $\mathrm{Si} / \mathrm{Al} 15$ ) has a BAS concentration of $0.86 \pm$ $0.05 \mathrm{~mol} / \mathrm{g}_{\mathrm{MFI}}$, corresponding to an ionic strength of $4.9 \pm 0.3$ $\mathrm{mol} / \mathrm{L}$. The ionic strength increases monotonically with the BAS concentration (Fig. 2A), and the curve bends at high BAS concentration, because of the expansion of unit cell at high $\mathrm{Al}$ concentration that dilute the volumetric concentration of $\mathrm{H}_{3} \mathrm{O}^{+}$hydr.

The non-ideality also impacts the catalytic reaction rate. In general, the TOF under a certain ionic strength TOF $(I)$ differs from that under ideal conditions $\mathrm{TOF}_{(\text {ideal })}$, i.e., TOF at zero ionic strength, by factors of the activity coefficient of ground state $\gamma_{\mathrm{GS}}(I)$ and transition state $\gamma_{\mathrm{TS}}(I)$ (Eq. 2A, detailed derivations are in supplementary text S1 and S2). The $\mathrm{TOF}_{\text {(ideal) }}$ is determined by $\Delta G^{\text {o }}$ (ideal), the free energy barrier under the ideal condition applying the transition state formula (Eq. 2B).

$$
\begin{gathered}
\operatorname{TOF}(I)=\operatorname{TOF}_{\text {(ideal) }} \cdot \frac{\gamma_{\mathrm{GS}}(I)}{\gamma_{\mathrm{TS}}(I)} \\
\mathrm{TOF}_{\text {(ideal) }}=\frac{k_{\mathrm{B}} T}{h} \exp \left(-\frac{\Delta G_{\text {(ideal) }}^{\circ}}{R T}\right)
\end{gathered}
$$

The $k_{\mathrm{B}}, h$, and $R$ denote the Boltzmann constant, Plank constant and ideal gas constant, respectively. The activity 
coefficient determines the excess chemical potential ( $\mu^{\text {excess }}$ ) according to $\mu^{\text {excess }}=R T \ln \gamma$. For the dehydration of cyclohexanol by $\mathrm{H}_{3} \mathrm{O}^{+}$hydr., it proceeds stepwise via association with $\mathrm{H}_{3} \mathrm{O}^{+}$hydr., protonation of the $\mathrm{OH}$ group, $\mathrm{C}-\mathrm{O}$ cleavage to form the cyclohexyl carbenium ion and deprotonation of the cyclohexyl carbenium ion (Fig. 2B). This stepwise mechanism is shown to dominate from low $\mathrm{H}_{3} \mathrm{O}^{+}$hydr. concentration $(<0.01$ $\mathrm{mol} / \mathrm{L}$ ) in homogeneous acids to high local $\mathrm{H}_{3} \mathrm{O}^{+}$hydr. concentration $(\sim 2.7 \mathrm{~mol} / \mathrm{L})$ in zeolite $(10,11)$. The free energy barrier is the energy difference between transition state, the deprotonation of cyclohexyl carbenium ion by water $\left(\mathrm{C}_{6} \mathrm{H}_{11}{ }^{+} \cdots\right.$ $\mathrm{H}_{2} \mathrm{O}$ ), and the ground state of adsorbed cyclohexanol associated with $\mathrm{H}_{3} \mathrm{O}^{+}$hydr. $\left(\mathrm{H}_{3} \mathrm{O}^{+}\right.$hydr. $\left.\cdots \mathrm{C}_{6} \mathrm{H}_{11} \mathrm{OH}\right)$. Cyclohexanol is a neutral molecule in the ground state, while it is a positively charged cyclohexyl carbenium ion $\left(\mathrm{C}_{6} \mathrm{H}_{11}{ }^{+}\right)$in the transition state. A neutral molecule is normally destabilized by the specific ionic strength $\left(\mu_{\mathrm{GS}}^{\text {excess }}>0\right.$ ), which is given by Eq. 3A showing a proportional increase with $I$. The term $K_{\mathrm{s}}$ denotes the Setschenow constant. In contrast, a cation or an anion is normally stabilized by the presence of an ionic environment $\left(\mu_{\mathrm{TS}}^{\text {excess }}<0\right.$ ), given by extended Debye-Hückel Equation (e.g., Truesdell-Jones Equation, Eq. 3B) where $a$ is the ion diameter, $A, B$ and $b$ are constants.

$$
\begin{gathered}
\mu_{\mathrm{GS}}^{\text {excess }}=2.303 \cdot R T K_{\mathrm{s}} I(3 \mathrm{~A}) \\
\mu_{\mathrm{TS}}^{\text {excess }}=2.303 R T \cdot\left(-\frac{A \sqrt{I}}{1+a B \sqrt{I}}+b I\right)
\end{gathered}
$$

As illustrated in Fig. 2B, the positive $\mu_{\mathrm{GS}}^{\text {excess }}$ and negative $\mu_{\mathrm{TS}}^{\text {excess }}$ in an ionic environment lead to a lower energy barrier compared to that under ideal conditions $\left[\Delta G^{\circ \neq}(I)<\Delta G^{0 \ddagger}\right.$ (ideal) $]$.

The rate of cyclohexanol dehydration by $\mathrm{HCl}$ in homogeneous aqueous solution showed a positive correlation with the ionic strength in concentrated $\mathrm{LiCl}$ solution (Fig. 2C, black line). Its TOF at $453 \mathrm{~K}$ is less than $0.01 \mathrm{~s}^{-1}$ at very low ionic strength, while it increased to more than $0.08 \mathrm{~s}^{-1}$ at high ionic strength of $\sim 5 \mathrm{~mol} / \mathrm{L}$. In analogy to $\mathrm{HCl}$, the TOF of cyclohexanol dehydration on H-MFI is replotted as a function of ionic strength (Fig. 2C, orange line). It increases with increasing ionic strength up to $\sim 2 \mathrm{~mol} / \mathrm{L}$, however, in contrast to $\mathrm{HCl}$ it drops at higher ionic strength.

To further explore the impact of ionic strength, a series of $\mathrm{Na}^{+}$partly exchanged H-MFI ( $\mathrm{Si} / \mathrm{Al} 45$ ) were prepared. Partly exchanging $\mathrm{H}_{3} \mathrm{O}^{+}$hydr. by $\mathrm{Na}^{+}$decreases the BAS concentration of H-MFI while maintaining the same ionic strength. As shown in Fig. 2D, with Na exchange degrees up to $75 \%$, the TOFs of H-Na-MFI remained unchanged, indicating that the variation of the concentration of hydrated hydronium ions while maintaining the ionic strength constant does not change the reaction rate. The comparison of $\mathrm{H}-\mathrm{Na}-\mathrm{MFI}(\mathrm{Si} / \mathrm{Al}$ 45) with a $\mathrm{Na}^{+}$exchange degree of $75 \%$ with $\mathrm{H}-\mathrm{MFI}(\mathrm{Si} / \mathrm{Al}$
200) exemplifies the impact the ionic strength. Both samples have identical BAS concentration ( 77 vs. $90 \mu \mathrm{mol} / \mathrm{g}_{\mathrm{MFI}}$ ), however, the former has a higher ionic strength than the latter ( 2.6 vs. $0.9 \mathrm{~mol} / \mathrm{L}$ ) and, indeed, the TOF is fourfold higher on $\mathrm{H}-\mathrm{Na}-\mathrm{MFI}(\mathrm{Si} / \mathrm{Al} 45)$ than on H-MFI ( $\mathrm{Si} / \mathrm{Al} 200)$, i.e., 0.082 vs. $0.021 \mathrm{~s}^{-1}$. Thus, these results demonstrate that it is not the location of hydronium ions or the hydronium ion concentrations, but the ionic strength that is critical for the specific catalyzed rate.

The free energy barrier and excess chemical potential in the reactions are shown in Fig. 2E. The decrease of $\mu_{\mathrm{TS}}^{\text {excess }}$ is more significant than the increase of $\mu_{\mathrm{GS}}^{\text {excess }}$, thus, the lower free energy barrier is caused in its majority by the stabilization of transition state. The inverse-volcano trend of $\mu_{\mathrm{TS}}^{\text {excess }}$ with ionic strength seems at first sight consistent with Eq. 3B that the negative first term dominates at low ionic strength, while the positive second term dominates at high ionic strength. However, the monotonic increase of TOFs with ionic strength at all concentrations under $\mathrm{HCl}$ catalysis exclude this possibility.

Next, we explore the reason for the rate drop with $\mathrm{H}_{3} \mathrm{O}^{+}$hydr. at higher concentrations. In variance to catalysis in aqueous $\mathrm{HCl}$, in $\mathrm{H}-\mathrm{MFI}$ both cyclohexanol and $\mathrm{H}_{3} \mathrm{O}^{+}$hydr. reside in the zeolitic micropore channels, and their relative locations are depicted in Fig. 3A. The average distance between two $\mathrm{H}_{3} \mathrm{O}^{+}$hydr. neighbors $\left(d_{\mathrm{h}-\mathrm{h}}\right)$ represents the distance between $\mathrm{H}_{3} \mathrm{O}_{\text {hydr. }}^{+} \mathrm{Z}$ pairs. The distance between their boundaries is $d_{\mathrm{b}-}$ $\mathrm{b}$, with volume of $V_{\mathrm{b}-\mathrm{b}}$. In this space between them resides the sorbed cyclohexanol. At molecular level, the change of electrolyte concentration is equivalent to the change of $d_{\mathrm{h}-\mathrm{h}}$ and $d_{\mathrm{b}-\mathrm{b}}$. Thus, the increase of BAS concentration in H-MFI leads to a shorter distance between $\mathrm{H}_{3} \mathrm{O}^{+}$hydr. inducing a decrease of $d_{\mathrm{h}-\mathrm{h}}, d_{\mathrm{b}-\mathrm{b}}$ and $V_{\mathrm{b}-\mathrm{b}}$. Figure $3 \mathrm{~B}$ shows that increasing BAS concentration from 0.05 to $0.86 \mathrm{mmol} / \mathrm{g}_{\text {MFI }}$ reduced the $d_{\mathrm{h}-\mathrm{h}}$ from 2.6 to $1.0 \mathrm{~nm}$ and the $d_{\mathrm{b}-\mathrm{b}}$ from 1.6 to almost $0.0 \mathrm{~nm}$. It should be noted here that the composition of $\mathrm{H}_{3} \mathrm{O}^{+}$hydr. $\left(\mathrm{H}^{+}\left(\mathrm{H}_{2} \mathrm{O}\right)_{8}\right)$ was determined to be invariant with temperature (supplementary text S3).

The individual energy level of reaction ground and transition states in terms of enthalpy $\left(\Delta H_{\mathrm{GS}}^{\circ}, \Delta H_{\mathrm{TS}}^{\circ}\right)$ and excess chemical potential $\left(\mu_{\mathrm{GS}}^{\text {excess }}, \mu_{\mathrm{TS}}^{\text {excess }}\right.$ ) on all studied H-MFI are depicted as a function of $d_{\mathrm{b}-\mathrm{b}}$ (Fig. 3, C and D). The enthalpy of ground state $\Delta H_{\mathrm{GS}}^{\circ}$ of sorbed cyclohexanol is stable at a distance $d_{\mathrm{b}-\mathrm{b}}$ larger than $0.8 \mathrm{~nm}$, while it increases sharply with the decrease of $d_{\mathrm{b}-\mathrm{b}}$ suggesting a repulsion between $\mathrm{H}_{3} \mathrm{O}^{+}$hydr. and sorbed cyclohexanol. The same trend is observed for $\mu_{\mathrm{GS}}^{\text {excess }}$. In contrast, the transition state has both $\Delta H_{\mathrm{TS}}^{\circ}$ and $\mu_{\mathrm{TS}}^{\text {excess }}$ in reverse-volcano curves with the minimum at $\sim 0.8$ $\mathrm{nm}$ and $\sim 0.6 \mathrm{~nm}$ of $d_{\mathrm{b}-\mathrm{b}}$. The $d_{\mathrm{b}-\mathrm{b}}$ of $0.8 \mathrm{~nm}$ is a critical distance 
at which $V_{\mathrm{b}-\mathrm{b}}$ is $0.2 \mathrm{~nm}^{3}$, the same volume of one cyclohexanol molecule in liquid phase. At this distance the volume between two neighboring $\mathrm{H}_{3} \mathrm{O}^{+}$hydr. is equal to the van der Waal (vdW) volume of cyclohexanol. At lower $d_{\mathrm{b}-\mathrm{b}}$, the $V_{\mathrm{b}-\mathrm{b}}$ becomes smaller than vdW volume of cyclohexanol, causing a strong $\mathrm{vdW}$ repulsion that increases the energy of the TS and decrease the TOF. In an open aqueous solution, the work to separate charges (hydronium ions and the anions of the zeolite) will be replaced only by a volume increase without constraining the sorbed alcohol.

Thus, we show how the bulkiness and the charges of $\mathrm{H}_{3} \mathrm{O}^{+}$hydr. constrained in zeolite micropores combine to influence the catalytic activity. For $\mathrm{H}-\mathrm{MFI}$, the $\mathrm{H}_{3} \mathrm{O}^{+}$hydr. is a cluster with a composition of $\mathrm{H}^{+}\left(\mathrm{H}_{2} \mathrm{O}\right)_{8}$ and has a specific volume, e.g., $\sim 0.24 \mathrm{~nm}^{3}$ at room temperature. It is anchored to the exchange sites of the zeolite framework by Coulombic forces and competes with substrate (e.g., cyclohexanol) to occupy the micropore volume. As the stabilization of water in the $\mathrm{H}^{+}\left(\mathrm{H}_{2} \mathrm{O}\right)_{8}$ ion is larger than the stabilization of the sorbed organic molecule, i.e., cyclohexanol, the latter adsorbs only in the volume between neighboring $\mathrm{H}^{+}\left(\mathrm{H}_{2} \mathrm{O}\right)_{8}$ in the micropore channel. This adds spatial constraints to substrate additional to that of micropore framework. At high $\mathrm{H}_{3} \mathrm{O}^{+}$hydr. concentrations, the volume between neighboring $\mathrm{H}^{+}\left(\mathrm{H}_{2} \mathrm{O}\right)_{8}$ becomes smaller than vdW volume of substrate. This leads to strong vdW repulsion between substrate and $\mathrm{H}^{+}\left(\mathrm{H}_{2} \mathrm{O}\right)_{8}$, and results in consequence in a decrease of the reaction rate. It should be noted in passing that such vdW repulsion might not apply for the case of smaller alcohols, e.g., ethanol, because they were shown capable replacing water molecules in the $\mathrm{H}_{3} \mathrm{O}^{+}$hydr. cluster, forming $\left(\mathrm{C}_{2} \mathrm{H}_{5} \mathrm{OH}\right)\left(\mathrm{H}_{3} \mathrm{O}^{+}\right)\left(\mathrm{H}_{2} \mathrm{O}\right)_{\mathrm{n}}$ cluster in zeolite channels (22).

Thus, the charge of $\mathrm{H}_{3} \mathrm{O}^{+}$hydr. creates an ionic environment that can be expressed as the ionic strength in H-MFI micropores. Such an environment increases the standard free energy/excess chemical potential of the substrate ground state, i.e., it destabilizes the uncharged reacting ground state of cyclohexanol. The ionic environment stabilizes the positively charged transition state. Both effects together lead to a decrease of the activation free energy and enhance so the reaction rate. Such ionic environments in zeolites will also exist with other solvents. For example, methanol forms protonated clusters $\mathrm{H}^{+}\left(\mathrm{CH}_{3} \mathrm{OH}\right)_{n}$ in small pores zeolites (23), which would additionally allow to stabilize the charged transition state via the modulating solvent permittivity (24).

The combination of the enhancement by the charged environment and the limitations by the additional spatial constraints from $\mathrm{H}_{3} \mathrm{O}^{+}$hydr. lead to a maximum in the catalytic activity of $\mathrm{H}_{3} \mathrm{O}^{+}$hydr. with varying $\mathrm{H}_{3} \mathrm{O}^{+}$hydr. concentrations. For $\mathrm{H}-\mathrm{MFI}$, the highest rates are observed when the volume between two neighboring $\mathrm{H}_{3} \mathrm{O}^{+}$hydr. equals to the vdW volume of substrate, i.e., concentrations of substrate and $\mathrm{H}_{3} \mathrm{O}^{+}$hydr. in the micropores are close to equal.

The final question arising is, however, how general these conclusions about reactivity in constrained environments are. To probe this, we explored a wide series of H-BEA zeolites (table S1) and report here the first results of this study. The dependence of the rate of alcohol dehydration on the concentration of hydronium ions exhibits an analogous volcano-like dependence (Fig. 4A). In particular, the variation of activation enthalpy and entropy with ionic strength show the similar profile shapes to H-MFI (Fig. 4, B and C), indicating the ionic strength influences catalytic activity via the identical mechanism. Note the curves shifting up and toward lower ionic strength on H-BEA compared to H-MFI, that is attributed to be the consequence of larger pore size of H-BEA that induces less vdW stabilization of transition state. It is to be expected that the specific enhancement and the position of the maximum will subtly depend on the size of the reacting molecule and the difference in polarity between the reacting substrate and the transition state. Overall, the results demonstrate unequivocally that the quantitative interpretation of the catalytic activity will allow prediction of the most suitable microporous catalyst for reactions in the presence of active sites being associated with ions.

\section{REFERENCES AND NOTES}

1. R. Gounder, E. Iglesia, Catalytic consequences of spatial constraints and acid site location for monomolecular alkane activation on zeolites. J. Am. Chem. Soc. 131, 1958-1971 (2009). doi:10.1021/ja808292c Medline

2. P. Tian, Y. Wei, M. Ye, Z. Liu, Methanol to olefins (MTO): From fundamentals to commercialization. ACS Catal. 5, 1922-1938 (2015). doi:10.1021/acscatal.5b00007

3. W. Vermeiren, J. P. Gilson, Impact of zeolites on the petroleum and petrochemical industry. Top. Catal. 52, 1131-1161 (2009). doi:10.1007/s11244-009-9271-8

4. E. T. C. Vogt, B. M. Weckhuysen, Fluid catalytic cracking: Recent developments on the grand old lady of zeolite catalysis. Chem. Soc. Rev. 44, 7342-7370 (2015). doi:10.1039/C5CS00376H Medline

5. G. L. Woolery, G. H. Kuehl, H. C. Timken, A. W. Chester, J. C. Vartuli, On the nature of framework Brønsted and Lewis acid sites in ZSM-5. Zeolites 19, 288-296 (1997). doi:10.1016/S0144-2449(97)00086-9

6. D. Barthomeuf, Conjugate acid-base pairs in zeolites. J. Phys. Chem. 88, 42-45 (1984). doi:10.1021/i150645a010

7. C. Mirodatos, D. Barthomeuf, Cracking of $n$-decane on zeolite catalysts: Enhancement of light-hydrocarbon formation by the zeolite field gradient. J. Catal. 114, 121-135 (1988). doj:10.1016/0021-9517(88)90014-0

8. H. Stach, J. Jaenchen, H. G. Jerschkewitz, U. Lohse, B. Parlitz, M. Hunger, Mordenite acidity: Dependence on the silicon/aluminum ratio and the framework aluminum topology. 2. Acidity investigations. J. Phys. Chem. 96, 8480-8485 (1992). doi:10.1021/i100200a051

9. A. Auroux, Acidity characterization by microcalorimetry and relationship with reactivity. Top. Catal. 4, 71-89 (1997). doi:10.1023/A:1019127919907

10. H. Shi, S. Eckstein, A. Vjunov, D. M. Camaioni, J. A. Lercher, Tailoring nanoscopic confines to maximize catalytic activity of hydronium ions. Nat. Commun. 8, 15442 (2017). doi:10.1038/ncomms15442 Medline

11. Y. Liu, A. Vjunov, H. Shi, S. Eckstein, D. M. Camaioni, D. Mei, E. Baráth, J. A. Lercher, Enhancing the catalytic activity of hydronium ions through constrained environments. Nat. Commun. 8, 14113 (2017). doi:10.1038/ncomms 14113 Medline

12. S. Wang, E. Iglesia, Catalytic diversity conferred by confinement of protons within porous aluminosilicates in Prins condensation reactions. J. Catal. 352, 415-435 (2017). doi:10.1016/j.jcat.2017.06.012 
13. A. J. Jones, S. I. Zones, E. Iglesia, Implications of transition state confinement within small voids for acid catalysis. J. Phys. Chem. C 118, 17787-17800 (2014). doi:10.1021/ip5050095

14. V. J. Margarit, M. Osman, S. Al-Khattaf, C. Martínez, M. Boronat, A. Corma, Control of the reaction mechanism of alkylaromatics transalkylation by means of molecular confinement effects associated to zeolite channel architecture. ACS Catal. 9, 5935-5946 (2019). doi:10.1021/acscatal.9b00763

15. S. Eckstein, P. H. Hintermeier, R. Zhao, E. Baráth, H. Shi, Y. Liu, J. A. Lercher, Influence of hydronium ions in zeolites on sorption. Angew. Chem. Int. Ed. $\mathbf{5 8}$, 3450-3455 (2019). doi:10.1002/anie.201812184 Medline

16. S. Schallmoser, T. Ikuno, M. F. Wagenhofer, R. Kolvenbach, G. L. Haller, M. Sanchez-Sanchez, J. A. Lercher, Impact of the local environment of Brønsted acid sites in ZSM-5 on the catalytic activity in n-pentane cracking. J. Catal. 316, 93102 (2014). doi:10.1016/i.j.cat.2014.05.004

17. W. O. Haag, R. M. Lago, P. B. Weisz, The active-site of acidic aluminosilicate catalysts. Nature 309, 589-591 (1984). doi:10.1038/309589a0

18. D. J. Parrillo, C. Lee, R. J. Gorte, Heats of adsorption for ammonia and pyridine in H-ZSM-5: Evidence for identical Brønsted-acid sites. Appl. Catal. A 110, 67-74 (1994). doi:10.1016/0926-860X(94)80106-1

19. A. Janda, A. T. Bell, Effects of Si/Al ratio on the distribution of framework Al and on the rates of alkane monomolecular cracking and dehydrogenation in H-MFI. J. Am. Chem. Soc. 135, 19193-19207 (2013). doi:10.1021/ja4081937 Medline

20. B. C. Knott, C. T. Nimlos, D. J. Robichaud, M. R. Nimlos, S. Kim, R. Gounder, Consideration of the aluminum distribution in zeolites in theoretical and experimental catalysis research. ACS Catal. 8, 770-784 (2018). doi:10.1021/acscatal.7b03676

21. D. H. Olson, G. T. Kokotailo, S. L. Lawton, W. M. Meier, Crystal-structure and structure-related properties of ZSM-5. J. Phys. Chem. 85, 2238-2243 (1981). doi:10.1021/ij150615a020

22. J. S. Bates, B. C. Bukowski, J. Greeley, R. Gounder, Structure and solvation of confined water and water-ethanol clusters within microporous Brønsted acids and their effects on ethanol dehydration catalysis. Chem. Sci. 11, 7102-7122 (2020). doi:10.1039/D0SC02589E Medline

23. J. R. Di lorio, A. J. Hoffman, C. T. Nimlos, S. Nystrom, D. Hibbitts, R. Gounder, Mechanistic origins of the high-pressure inhibition of methanol dehydration rates in small-pore acidic zeolites. J. Catal. 380, 161-177 (2019). doi:10.1016/i.jcat.2019.10.012

24. D. Y. Murzin, Solvent effects in catalysis: Implementation for modelling of kinetics. Catal. Sci. Technol. 6, 5700-5713 (2016). doi:10.1039/C6CY00495D

25. W. Luo, W. Cao, P. C. A. Bruijnincx, L. Lin, A. Wang, T. Zhang, Zeolite-supported metal catalysts for selective hydrodeoxygenation of biomass-derived platform molecules. Green Chem. 21, 3744-3768 (2019). doi:10.1039/C9GC01216H

26. Y. Zhi, H. Shi, L. Mu, Y. Liu, D. Mei, D. M. Camaioni, J. A. Lercher, Dehydration pathways of 1-propanol on HZSM-5 in the presence and absence of water. J. Am. Chem. Soc. 137, 15781-15794 (2015). doi:10.1021/jacs.5b09107 Medline

27. S. Prodinger, H. Shi, H. Wang, M. A. Derewinski, J. A. Lercher, Impact of structural defects and hydronium ion concentration on the stability of zeolite BEA in aqueous phase. Appl. Catal. B 237, 996-1002 (2018). doi:10.1016/i.apcatb.2018.06.065

28. M. A. Camblor, A. Corma, S. Valencia, Synthesis in fluoride media and characterisation of aluminosilicate zeolite beta. J. Mater. Chem. 8, 2137-2145 (1998). doi:10.1039/a804457k

29. S. Eckstein, P. H. Hintermeier, M. V. Olarte, Y. Liu, E. Baráth, J. A. Lercher, Elementary steps and reaction pathways in the aqueous phase alkylation of phenol with ethanol. J. Catal. 352, 329-336 (2017). doi:10.1016/i.jcat.2017.06.002

\section{ACKNOWLEDGMENTS}

We thank O.Y. Gutiérrez and D.M. Camaioni for fruitful discussions, and S. Prodinger and M.A. Derewinski for providing the H-BEA zeolite. Funding: This work (J.A.L. and S.K.) was supported by the U.S. Department of Energy (DOE), Office of Science, Office of Basic Energy Sciences (BES), Division of Chemical Sciences, Geosciences and Biosciences (Transdisciplinary Approaches to Realize Novel Catalytic Pathways to Energy Carriers, FWP 47319). G.L.H. was supported by the DOE Office of Science and BES, Division of Chemical Sciences, Geosciences and Biosciences, under grant No. DE-FG02-01ER15183, to Yale University,
Department of Chemical and Environmental Engineering, New Haven, CT 06520. Author contributions: Yue L. and J.A.L. conceived the research; N.P. did the catalytic reaction by $\mathrm{HCl}$ and determined the activation energy on $\mathrm{H}-\mathrm{MFI}$; P.H.H., S.H., L.M., Yuanshuai L. and E.B. measured the physicochemical property and catalytic activity of H-MFI, wherein P.H.H. first reported the volcano-like activity of H-MFI; S.E. and Q.L. measured the adsorption property of H-MFI; S.K. measured the reactions on H-BEA; G.L.H. helped analyzing the data. Competing interests: The authors declare no competing interest. Data and materials availability: All data are available within the main text and its Supplementary Material files.

\section{SUPPLEMENTARY MATERIALS}

science.sciencemag.org/cgi/content/full/science.abh3418/DC1

Materials and Methods

Supplementary Text S1 to S3

Figs. S1 to S5

Table S1

References (27-29)

2 March 2021; accepted 23 April 2021

Published online 6 May 2021

10.1126/science.abh3418 

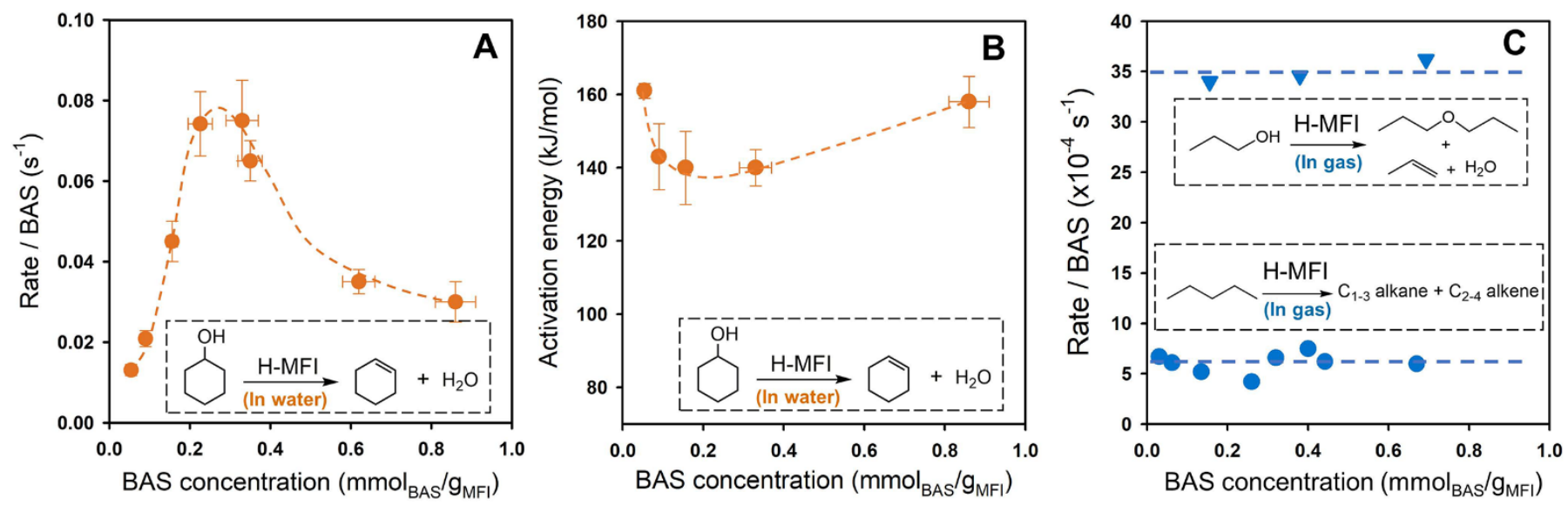

Fig. 1. Brønsted acid site (BAS) normalized reaction rate in $\mathrm{H}-\mathrm{MFI}$ catalyzed reactions in water and gas phase. ( $A$ and $B$ ) Rate at $423 \mathrm{~K}(\mathrm{~A})$ and activation energy $(\mathrm{B})$ of cyclohexanol dehydration on $\mathrm{H}-\mathrm{MFI}$ with different BAS concentrations in water. (C) Cracking of $n$-pentane at $763 \mathrm{~K}$ (circles) and dehydration of 1-propanol at $433 \mathrm{~K}$ (triangles) on $\mathrm{H}$-MFI with different BAS concentrations in the gas phase. Data for $n$-pentane cracking is from (25) and (16); data for 1-propanol dehydration on $\mathrm{H}-\mathrm{MFI}$ with $0.69 \mathrm{mmol} / \mathrm{g}_{\mathrm{MFI}}$ is from (26). 

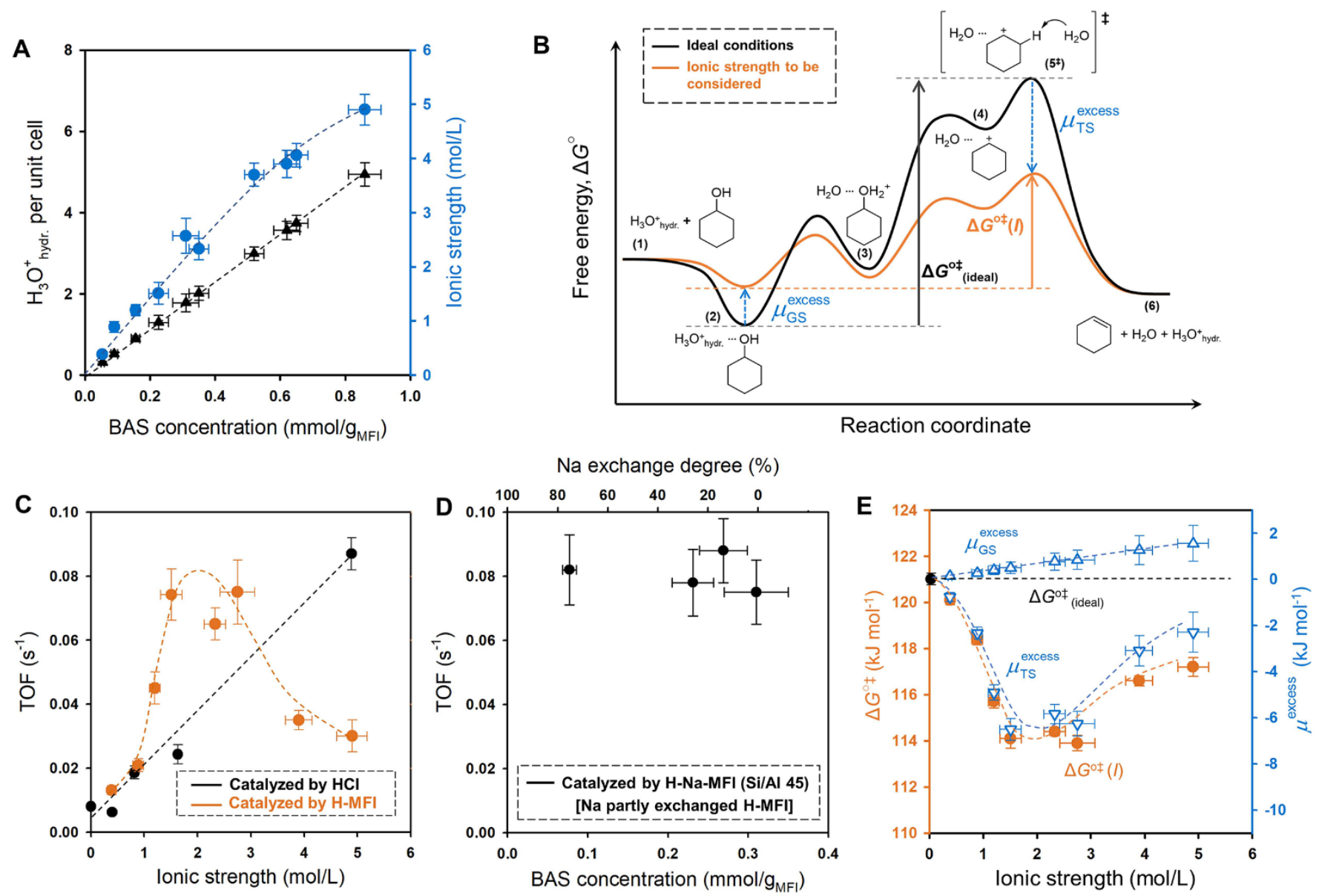

Fig. 2. Impact of local $\mathrm{H}_{3} \mathrm{O}^{+}$hydr. concentration and ionic strength on the dehydration of cyclohexanol catalyzed by $\mathrm{H}_{3} \mathrm{O}^{+}$hydr. (A) Unit cell normalized concentrations of $\mathrm{H}_{3} \mathrm{O}^{+}$hydr. (triangles) and ionic strength (circles) as a function of BAS $\left(\mathrm{H}_{3} \mathrm{O}^{+}{ }_{\text {hydr. }}\right.$ ) concentration. (B) Elementary steps and their energies in dehydration of cyclohexanol on $\mathrm{H}_{3} \mathrm{O}^{+}$hydr. in $\mathrm{H}-\mathrm{MFI}$ zeolite in water under ideal and non-ideal conditions. (1) reactant cyclohexanol and $\mathrm{H}_{3} \mathrm{O}^{+}$hydr.; (2) cyclohexanol associated with $\mathrm{H}_{3} \mathrm{O}^{+}$hydr.; (3) protonated cyclohexanol; (4) cyclohexyl carbenium ion; (5 $5^{\ddagger}$ transition state of deprotonation of cyclohexyl carbenium ion by water; (6) product cyclohexene, water and $\mathrm{H}_{3} \mathrm{O}^{+}$hydr. The " $\mathrm{H}_{2} \mathrm{O} \cdots$ " represents the interactions with solvent water. (C) TOF as a function of ionic strength under the catalysis of $\mathrm{HCl}$ (black circles) at $453 \mathrm{~K}$ and $\mathrm{H}$-MFI (orange circles) at $423 \mathrm{~K}$. The ionic strength in $\mathrm{HCl}$ solution is varied by the changing the concentration of $\mathrm{LiCl}$ electrolyte. (D) TOF of $\mathrm{Na}$ partly exchanged H-MFI (Si/AI 45). (E) Reaction free energy barriers and excess chemical potential of ground (GS) and transition state (TS) under the ideal condition and under an ionic strength. The calculation of free energy barriers and excess chemical potential are in supplementary text S1. 

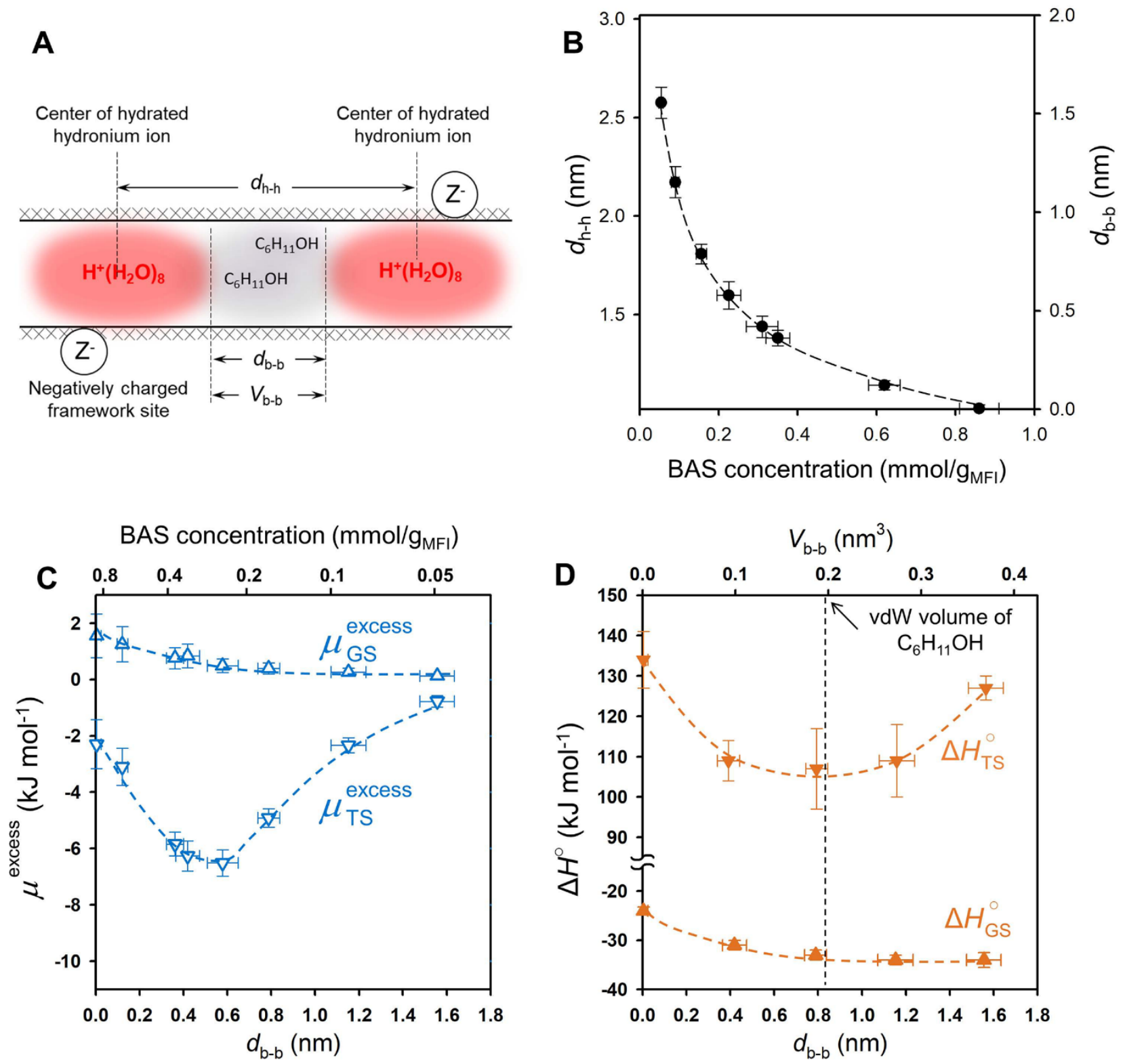

Fig. 3. Impact of the distance between $\mathrm{H}_{3} \mathrm{O}^{+}$hydr. in $\mathrm{H}-\mathrm{MFI}$ micropore on the energy of the ground state (GS) and the transition state (TS) of cyclohexanol dehydration catalyzed by $\mathrm{H}_{3} \mathrm{O}^{+}{ }_{\text {hydr. }}$. (A) Schematic illustration of $\mathrm{H}_{3} \mathrm{O}^{+}$hydr. and cyclohexanol in $\mathrm{H}-\mathrm{MFI}$ micropore channels and the mean distance $d_{h-h}$ between two neighboring $\mathrm{H}_{3} \mathrm{O}^{+}$hydr., the mean distance $d_{\mathrm{b}-\mathrm{b}}$ and volume $V_{\mathrm{b}-\mathrm{b}}$ between the boundaries of neighboring $\mathrm{H}_{3} \mathrm{O}^{+}$hydr. (B) The $d_{h-h}$ and $d_{b-b}$ as a function of BAS concentration. ( $C$ and D) Excess chemical potential (C) and enthalpy of ground and transition state (D) as a function of $d_{b-b}$ and $V_{b-b}$. The $d_{h-h}$ is estimated by the cubic root of the average zeolite volume normalized to the number of $\mathrm{H}_{3} \mathrm{O}^{+}$hydr.; the $d_{\mathrm{b}-\mathrm{b}}$ is calculated by subtracting the length of $\mathrm{H}_{3} \mathrm{O}^{+}{ }_{\text {hydr. }}$ from $d_{\mathrm{h}-\mathrm{h}}$; the $V_{\mathrm{b}-\mathrm{b}}$ is calculated by a cylinder model with length of $d_{\mathrm{b}-\mathrm{b}}$ and the diameter of $\mathrm{H}-\mathrm{MFI}$ micropore channel. 

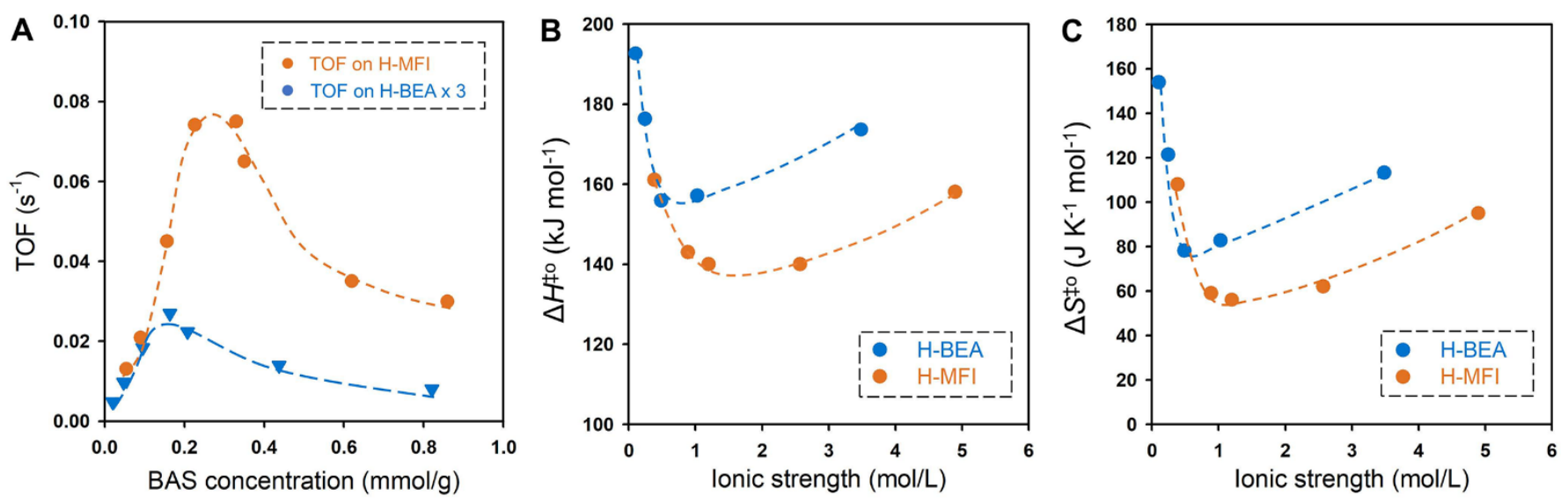

Fig. 4. Comparison of the dehydration reactions of cyclohexanol catalyzed by $\mathrm{H}_{3} \mathrm{O}^{+}$hydr. in $\mathrm{H}-\mathrm{MFI}$ and H-BEA. (A) Impact of BAS concentration on the TOF at $423 \mathrm{~K}$. (B and C) Activation enthalpy $\left(\triangle H^{\ddagger 0}\right)(B)$ and activation entropy $\left(\triangle S^{\ddagger 0}\right)(\mathrm{C})$ as a function of ionic strength. 